Knut De Swert

2010

Marc Hooghe

\title{
When do Women get a Voice? \\ Explaining the Presence of Female News Sources in Belgian News Broadcasts (2003- 2005)
}

\section{European Journal of Communication, 25(1), 69-84.}

(C) Sage Publications, Thousand Oaks, 2010.

DOI : 10.1177/0267323109354229. European J ournal of Communication, Impact Factor 0.682

SUMMARY OF THE ARTICLE

\begin{abstract}
For more than a decade now, it has been demonstrated that female news sources receive little attention in television news. Usually women account for no more than 20 to 25 per cent of all the time devoted to people speaking in the news. In this article we assess when exactly female news sources are depicted in the news. We use a 25,896 item and 1,600 hours of television news dataset, covering public broadcasting and commercial television in Belgium (Flanders) for the years 2003 to 2005. The analysis shows that female news sources are strongly stereotyped and limited to traditional 'female' topics. The impact of the gender of the reporter was limited. Contrary to expectations the broadcasting corporation with a longstanding gender diversity policy actually scored worse than its counterpart without such a policy. In the conclusion, we discuss the apparently difficult relation between traditional news standards and depicting gender diversity.
\end{abstract}

Keywords: broadcast news, gender diversity, Belgium, gender representation, reporters, public broadcasting 


\section{Introduction}

Mass media, and television broadcast in particular are often being accused of contributing to the reproduction of cultural stereotypes within society. The media tend to depict women and members of minority groups in a limited and stereotyped manner. This is especially the case for news broadcasts, which enjoy a high status as they allegedly portray a reliable picture of what happens in the real world. As such, news broadcasts should allow for a fair and unbiased representation of all groups within the population. Reality, however, often falls short of these high expectations. Research indicates that the selection of news sources, i.e., actors appearing in a news broadcast and delivering a statement, remains heavily biased. In 1995, the Global Media Monitoring Project conducted a study simultaneously in 71 countries, demonstrating that women account for no more than 21 per cent of all news sources in television news broadcasts. Five and ten years later, the study was repeated with almost identical results: the percentage of female news sources remained 22 per cent (Spears \& Seydegart 2000; Gallagher 2006, 22). Although this global project certainly could be criticized on methodological grounds ${ }^{1}$, the stability of the results remains remarkable. Between 1995 and 2005, all over the world women have gradually acquired more leading positions in the political, cultural, scientific domain. Despite these upward trends, television news still seems to depict the same gender representation as it did several decades ago. This systematic and apparently very persistent underrepresentation of women in television news poses serious problems for the way news media report on reality. For Tuchman (1978), this could even be considered as a "symbolic annihilation" of the female perspective, and of women in society in 
general. Current figures suggest that female presence remains as low as ever, despite the fact that gradually women have made progress toward gender equality in society as a whole.

To add injury to insult: the problem is not just quantitative. If women get a voice in the news, this often still happens in a stereotyped manner, despite various efforts to increase the number of female experts being interviewed (Van Zoonen 1998b; Carroll \& Schreiber 1997). Other studies show that women in news broadcasts are often associated with traditionally 'feminine' topics, like child care, health, family matters, while they are largely absent in topics like law, finance, economy or foreign affairs (Craft \& Wanta 2004). And finally, studies on newspapers and television news also show that when women are interviewed, the average amount of the time or space they are allotted is significantly smaller than for male interviewees (Van Zoonen 1994; Mills 1990; Lefever 2004; Len-Rios et al. 2005).

In this article we want to go beyond the conventional approach of just measuring the percentage of female news sources. Based on a multivariate regression model, we want to determine when women are selected as news sources. We define a news source as any actor appearing in a news item and delivering a text of at least one sentence. We use this definition because we can assume that visibility in broadcast news has a stronger impact on stereotyping than a mere mentioning of actors. Our case study uses all news broadcasts of a three year period (2003, 2004 and 2005), broadcast by the two major television stations in Flanders (Belgium).

We use a multivariate approach, because we can assume that gender stereotyping can be 
caused by a number of elements. Shoemaker and Reese (1996) list five environmental influences on news content: the individual level of the journalists' background, institutional pressure at the organizational level, newsgathering routines (media routines level), the relationship with news sources in the extra-media level and finally the influence of ideological values. Possible barriers for the access of female news sources to the news can be situated in each one of these fields. In this study, we mainly check for influences of the individual level of the journalist (male versus female), institutional pressure (gender policy or not) and the media routines level (bias in the editing process, presence of traditionally 'female' topics in the news). It is important to identify in a more precise manner how and where exactly these various forms of bias operate. Determining the exact bias is a crucial first step for any policy designed to counter the underrepresentation of women.

\section{(...)}

\section{Data and Methods}

To ascertain what exactly determines the likelihood that a female news source will receive airplay, we rely on the analysis of a comprehensive dataset, covering 41,000 news items, accounting for the entire news production of the Flemish public broadcasting corporation VRT and the main commercial station VTM between January, 12003 and December, 31 2005. These 41,000 items were collected by the Belgian Electronic News 
Archive (www.nieuwsarchief.be) and they represent one of the largest digital news archives available for scientific research (Hooghe et al., 2005). For every news item, there was a thematic encoding as well as a news source encoding, involving the registration of the name, function, gender, language and speaking time of all people who got to say at least one sentence on camera. Coding of items and news sources was performed by a team of professional encoders that were trained and controlled by the academic staff of the News Archive. Inter-encoder reliability was tested frequently and the mean Cohen's Kappa values for the variables used in this article vary from 0.79 till 0.96 .

\section{(...)}

The impact of the reporters' gender can be measured by including information on the reporter who made the item. The ENA contains the name of every journalist who was acknowledged as the reporter responsible for the news item. This leads to the independent variable 'News item made by a female reporter'. While it is common practice in Belgium to list the name of the reporter at the start of the news item, this practice is not always continued for short items. This lack of information reduces our dataset from 25,896 to 15,812 news items. For this variable, we introduce a distinction between items made by female reporters ( 36 per cent of all items), by male reporters (61 per cent) and by a mixed female/male team (three per cent of the items).

Hypothesis three states that news items in which female news sources appear are considered as less important than those in which male news sources appear. Given the conventional structure of news broadcasts (starting with the headlines to finish with less 
important items), we operationalized this variable by including the rank order of the item in which the news source appears. This ordinal variable ranges from 1 (the first item in the news, and we can assume this is the most important one) to 25 (an item closing the news broadcast). For hypothesis four (progress over time), we can simply include the observation period (2003-2004-2005), and our fifth hypothesis leads to a dichotomy between networks with a diversity policy (i.e., VRT) and the one without (i.e., VTM).

\section{(....)}

\section{Multivariate Analysis}

In our multivariate effort to explain the presence of female news sources, we will use two different methods. First, we rely on binary logistic regression to answer the question whether a female news source is present in the item (dichotomy: present/not present). Subsequently, linear regression techniques will be used to assess the determinants of the time allotted to female news sources.

With regard to the binary logistic regression (Table 3), we have to acknowledge that the explained variance (Nagelkerke's $\mathrm{r}^{2}$ ) remains rather low with a value of .04. This kind of low explained variance, however, is not exceptional give the large size of our dataset $(n=15,812)$, and the huge variety of topics being covered. One needs to keep in mind that in an ideal situation, we would arrive at an explained variance of zero, since none of our 
independent variables should really make a difference then. In the research period though, the study shows that three independent variables remain clearly significant. We can observe that female news sources are being depicted much more often in items covering a 'female' topic. The odds that a female news source will be depicted in one of these items are about twice as high in comparison to other topics. The fact that the item has been produced by a female reporter has only a limited effect although the effect remains significant at the .01 level. The low value of the Wald statistic demonstrates that the influence of female reporters is relatively limited.

The hypothesis that female news sources are chosen for the least important news items is not confirmed at all, since the rank order of the item does not have any significant effect on the chances that a female news source will be depicted. The time hypothesis, on the other hand, does receive confirmation, as the presence of female news sources increases over time. The most surprising result of this analysis is the negative effect of public broadcasting. The fact that a news item has been broadcast on public television has a strong and significant impact on the likelihood that a female news source will be included. It is important to repeat here that this is a controlled effect, since we also included the other variables in the analysis. Even controlling for the gender segregation of the topics, VRT news systematically depicts fewer women, despite its gender diversity plan. This result is completely counterintuitive. In evaluation research it is not uncommon that a gender diversity plan does not have any effect (Stout $\&$ Stevens 2000). It is quite exceptional however, that the relation is significant, but negative, implying that a gender diversity plan is associated with less gender diversity. 
Table 3. Likelihood that an Item Includes a Female News Source

\begin{tabular}{llrr}
\hline & Coefficient B & Wald & \multicolumn{1}{c}{ Likelihood } \\
\hline "Female" topic & $0.634^{* * *}$ & 296.97 & 1.885 \\
Female reporter & $0.089^{* *}$ & 6.72 & 1.093 \\
Order in the News & 0.002 & 0.38 & 1.002 \\
Public broadcasting & $-0.279^{* * *}$ & 71.37 & 0.756 \\
Time Period & $0.040^{* * *}$ & 8.10 & 1.041 \\
Cte. & $-0.784^{* * *}$ & & \\
\hline
\end{tabular}

Entries are the result of a binary logistic regression. Dependent variable: presence of at least one female news source in that item. Nagelkerke's $r^{2}: .04 . n=15,812$ news items.

Sign.: $* * *:<.001 ; * *:<.01 ; *:<.05$. Odds ratio $>1=$ female news source is more likely.

$(\ldots$.

\section{Discussion}

For more than a decade now, several studies have shown that women tend to be largely absent in broadcast news world wide. While gender diversity has been gaining ground very rapidly in Belgian society (especially visible in politics, both in legislation as in practice), the gender balance of the main news broadcasts changes rather slowly. Obviously, the television news is not always in sync with real changes in society.

From our multivariate analysis, the main determinant of the presence of female news sources proved to be the gendered nature of the topic of the news item. If women are depicted as news sources, this is usually in the context of traditionally female topics like family, education and health care. This means that if one is interested in simply increasing the percentage of female news sources, a quick and easy solution would be to increase the attention devoted to 'soft' topics like health, family and education. However, in that case too the problem of gender segregation and stereotyping would remain just as 
strong. Speaking in a purely quantitative way, the presence of female news sources would increase but this would not change anything about the problem of stereotyping. This could serve as a warning that simply setting quantitative goals will not be sufficient. If one wants to reduce gender stereotyping in news content, it is important that the presence of female news sources rises just as well in traditionally ‘male' topics.

Increasing the number of female reporters on the news desk, by itself, is clearly not sufficient as a solution either. While we did observe a significant relation between the gender of the reporter and the time allotted to female news sources, this effect was limited: there does not seem to be all that much of a difference between female and male reporters. Female and male reporters alike share the same working methods and selection criteria, and our findings support the job model rather than the gender model.

Given the various calls for an explicit gender equality policy in newsrooms, our final finding might be the most problematic one. Our multivariate analysis shows that the public network, which has implemented a diversity policy for almost two decades by now, scores worse than the private channel which does not have such a policy initiative whatsoever.

It is not clear how this puzzling phenomenon can be explained. Could it be that reporters in general tend to be so independent-minded that any outside initiative to prescribe whom they should interview can actually lead to exactly the opposite effect? In that case, any effort to develop a gender diversity policy for news desks should take extreme care not to be perceived as an outside intervention limiting editorial autonomy. But this is probably 
not the main factor. Gender diversity seems to be linked to several editorial choices, of which topic selection is just one (important) aspect that does not offer sufficient explanation for the skewed gender representation between public and private broadcasting. Other factors, not included in our study, could be at play. A specific study of actor selection could be interesting in this perspective. It could well be the case that the preference of commercial stations for non-institutional news sources - regardless of the topic - is a key element to unravel this puzzling difference in gender representation. In Flanders, at least, the commercial station has a preference for bringing news 'close at home', featuring common people (where possible) almost as a mission statement and this might have a direct effect on the gender balance of the news sources. But even if this would prove to be the case, this is not reassuring. If one strives to depict gender diversity in society in a realistic manner, showing more women in non-institutional or nonrepresentative roles is not the main target, as we assume that female news sources should be represented in various social roles and settings. How exactly this goal of gender equality can be reached within the framework of more traditional, and therefore more institutionally oriented news norms, remains a topic for further in-depth investigation.

Endnote

${ }^{1}$. The main methodological problem with GMMP is that it is based on a sample of a single day, which is simply too small. It is not uncommon that certain news events, both national and international, occupy a large part of the news cast of the day. News events are not necessarily gender neutral, and the gender division of the main actors featuring that event would have a large impact on the results of the Monitor for that country. Moreover, we find relatively large day-to-day differences in the gender portrayal in Belgian news broadcasts over hundreds of news days. From a methodological perspective, GMMP calculations should use an error of margin larger than any potential tendency over a five year period. 